\title{
Workplace Violence against Healthcare Professionals - A Cross-Sectional Study to Assess the Current Scenario in Chennai City, India
}

\author{
Ramakrishnan Kesavan¹, Vinita Mary Abraham², Vishwani Reddy³, Tanaaz Khan ${ }^{4}$, Vishali Sankar ${ }^{5}$, Swathi R. ${ }^{6}$ \\ ${ }^{1}$ Department of Public Health Dentistry, Dr. MGR Educational and Research Institute (Deemed to Be \\ University), Chennai, Tamilnadu, India. ${ }^{2}$ Department of Public Health Dentistry, Dr. MGR Educational and \\ Research Institute (Deemed to Be University), Chennai, Tamilnadu, India., ${ }^{3}$ Department of Public Health \\ Dentistry, Dr. MGR Educational and Research Institute (Deemed to Be University), Chennai, Tamilnadu, India. \\ ${ }^{4}$ Department of Public Health Dentistry, Dr. MGR Educational and Research Institute (Deemed to Be \\ University), Chennai, Tamilnadu, India. ${ }^{5}$ Department of Public Health Dentistry, Dr. MGR Educational and \\ Research Institute (Deemed to Be University), Chennai, Tamilnadu, India. ${ }^{6}$ Department of Public Health \\ Dentistry, Dr. MGR Educational and Research Institute (Deemed to Be University), Chennai, Tamilnadu, India.
}

\section{ABSTRACT}

\section{BACKGROUND}

Workplace violence against health workers is offensive and harms the psychological and physical well-being of health-care staff. It affects their job motivation leading to compromise in the quality of care provided. The present study was conducted to assess the prevalence and potential risk factors associated with workplace violence against medical and dental healthcare professionals in Chennai city.

\section{METHODS}

A descriptive cross-sectional survey was done among 440 healthcare professionals from medical and dental settings. A specially designed validated questionnaire consisted of 15 questions divided into 3 sections was used to collect the demographic details, experience and factors associated with workplace violence.

\section{RESULTS}

The overall prevalence of workplace violence in the current study was $38 \%$, with male participants reporting a higher prevalence than females. $51.4 \%$ of the respondents believe that the lack of proper communication and negligence of the doctor also plays a crucial role in violence against them. More than half of the participants (61.4\%) recommended doctors to carry weapons for self-defence against violence and these values rise to $71 \%$ among individuals with more than 10 years of clinical experience. Around $70.5 \%$ believed that media publicity plays a crucial role in the increasing trend of violence against healthcare professionals.

\section{CONCLUSIONS}

Workplace violence against doctors in Chennai is frequent although in most of the situations it is psychological. Healthcare staff should be trained to identify, manage and prevent violent situations adequately. A nationwide law for the prevention of violence against healthcare professionals and institutions should be developed.

\author{
Corresponding Author: \\ Dr. Ramakrishnan Kesavan, \\ Associate Professor, \\ Department of Public Health Dentistry, \\ Dr. MGR Educational and Research \\ Institute (Deemed to Be University), \\ Chennai, Tamilnadu, India. \\ E-mail: keshavan84@gmail.com
}

DOI: $10.14260 /$ jemds/2020/547

How to Cite This Article: Kesavan R, Abraham VM, Reddy V, et al. Workplace violence against healthcare professionals- a cross-sectional study to assess the current scenario in Chennai city, India. J Evolution Med Dent Sci 2020;9(35): 2515-2520,

DOI: $10.14260 /$ jemds/2020/547

Submission 28-05-2020,

Peer Review 22-07-2020,

Acceptance 22-07-2020,

Published 31-08-2020.

Copyright (C) 2020 JEMDS. This is an open access article distributed under Creative Commons Attribution License [Attribution 4.0 International (CC BY 4.0)]

\section{KEY WORDS}

Workplace Violence, Health Personnel, Psychological, Risk Factor, Motivation 


\section{BACKGROUND}

Violence against health care workers is a universal entity broadly described all over the world. Around $8 \%$ to $38 \%$ of all health care workers suffer violence at some point of time in their occupations. ${ }^{1}$ According to the National Institute of Occupational Safety and Health (NIOSH), Workplace violence (WPV) is defined as "violent acts (including physical assaults and threats of assaults) directed toward persons at work or on duty". ${ }^{2}$ Workplace violence can be physical when it involves the use of physical force against individuals and includes beatings, slaps, kicks, stabbings, shoves, shootings and bites; or psychological violence when it is a verbal abuse, disrespect, rude behaviour, intimidation, harassment and bullying. ${ }^{3}$ Workplace violence can be a solitary event or several small and recurrent incidents that cumulatively have the potential to cause severe harm to the health care worker. ${ }^{4}$

WPV against health workers is offensive and has an adverse impact on the psychological and physical well-being of health-care staff. It affects their job motivation, and as a consequence, there is a compromise in the quality of care provided. ${ }^{1}$ In most of the situations, violence is perpetrated by patients and their accompanying persons. Also, health workers may become the targets of collective or political violence during disaster and conflict situations. Categories of health workers most at risk include doctors, nurses and other staff directly involved in patient care are at high risk of workplace violence. ${ }^{1}$ Violence against Health care workers is an underreported, ubiquitous, and persistent problem that has been largely tolerated and ignored in healthcare settings especially when it is of non-physical forms. ${ }^{5}$ Reasons for underreporting such incidents include guilt or shame, fear of being blamed, revenge by the aggressor and lack of time and unwillingness to face the consequences. In certain cases, there is a belief that sufficient action will not be taken by the officials. $4^{4}$

In India, where the society is predominantly capitalistic, health-care is probably the only profession which still works on welfare model at least in the government institutions. This ensures a ranked and economical health-care delivery to almost the entire population. ${ }^{6}$ Chennai is one of the fastestgrowing metropolitan cities in India; and with an evergrowing population, the need for comprehensive health care also increased swiftly. The city has a glorious tradition of medical care. The Government General Hospital at Madras (now Chennai) was started in 1664. It continues to be one of the oldest, largest and foremost government hospitals in India. ${ }^{7}$ The development of the IT (Information Technology) corridor and special economic zones led to the establishment of numerous corporate hospitals in these regions. A wide range of single and multi-speciality hospitals with advanced medical facilities, operated by distinguished doctors makes Chennai, 'the medical capital' of India. These hospitals bring in an estimated 150 international patients every day. It attracts about $45 \%$ of health tourists from overseas arriving in the country and 30 to 40 per cent of domestic health tourists. It is a matter of pride that the city has overturned what in earlier times was 'medical tourism' from India to other countries for specialised care to 'reverse medical tourism' where people from abroad has turned to India and specifically Chennai, for quality medical care. ${ }^{7}$
Although reported sporadically by the press, there is a lack of research about violence against health care professionals in Chennai. Doctors play a key role in healthcare systems, so it is important to study the prevalence and nature of their exposure to workplace violence.

Therefore the present study was conducted to assess the prevalence, potential risk factors associated with and possible consequences of workplace violence against medical and dental healthcare professionals in Chennai.

\section{METHODS}

A cross-sectional survey was done among 440 healthcare professionals from medical and dental settings. The study was conducted between January and March of 2020.

\section{Ethical Clearance}

The study was conducted following the Helsinki Declaration as revised in 2013. The protocol was submitted to the ethical committee before the start of the study and approval was obtained from the Institutional Review Board.

\section{Questionnaire Development and Pilot Study}

The questionnaire for the current study was specially designed and consisted of 15 questions which were divided into 3 sections. The first section was used to record the participants' demographic details. The second and third sections consisted of questions related to the prevalence of workplace violence and various factors associated with it. A pilot study was conducted among 40 participants from the target population to validate the questionnaire and to get the required sample size. The internal consistency of the questionnaire was adequate (Cronbach's alpha $=0.75$ ). The reliability of the tool was evaluated by test-retest and Kappa statistic (0.85). A panel of experts weighed the content and face validity of the questionnaire and assessed whether the items are adequately measuring the intended construct and are sufficient to measure the domain of interest. Training and calibration of the investigators was done in the department of public health dentistry.

\section{Sample Size Calculation}

The appropriate sample size for the current study was determined by the prevalence of workplace violence in the pilot study which was $36 \%$. With the Alpha error at $5 \%$ and $95 \%$ confidence level, the estimated sample size was calculated by the following formula:

$\mathrm{N}=\frac{\mathrm{t}^{2} \mathrm{Xp}(1-\mathrm{p})}{\mathrm{m}^{2}}$

Where:

$\mathrm{n}=$ required sample size

$\mathrm{t}=$ confidence level at $95 \%$ (standard value of 1.96)

$\mathrm{p}=$ estimated prevalence

$\mathrm{m}=$ margin of error at $5 \%$ (standard value of 0.05 ) 


$$
\begin{aligned}
\mathrm{n} & =\frac{1.96^{2} \times .36(1.36)}{0.50^{2}} \\
& =\frac{3.8416 \times .2304}{.002} \\
& =\frac{.8861^{2}}{.002} \\
& =433 \sim 440
\end{aligned}
$$

\section{Sampling Methodology and Data Collection}

A non-probabilistic convenient sampling methodology was used to recruit the participants for the present study. Approachable health care professionals having a clinical practice within a defined geographic area were involved. The questionnaire encompassed a separate section that explained the nature and purpose of the study along with an informed consent form. After obtaining the written informed consent from the participants, the questionnaire was distributed by the investigator and all the questions were explained clearly to avoid any ambiguity. The respondents were requested to provide appropriate answers and were assured of anonymity and confidentiality. The filled questionnaire was collected on the same day and individuals who were absent after multiple visits and or not willing to provide informed consent were excluded from the study.

\section{Statistical Analysis}

The data was analysed using Statistical Package for Social Sciences, IBM Corporation, SPSS Inc., Chicago, IL, USA version 21 software package (SPSS). Descriptive statistics with frequency, percentage, mean and standard deviation was computed. Pearson Chi-square test and Fisher's Exact test was used to assess the level of significance at $\mathrm{p}<0.05$.

\section{RESULTS}

The age of the participants in the present study ranged between 24 and 77 years with a mean age of $37.6 \pm 11.4$ years. Around $53.6 \%$ were males and the respondents were equally distributed among medical and dental profession (50\%). About $41.4 \%$ have clinical experience of less than 5 years, 33.6 $\%$ between 5 to 10 years and $25 \%$ more than 10 years (Table 1). A total of $89 \%$ of the respondents were aware of the increasing trend in workplace violence among doctors in India. This percentage goes up to $92.7 \%$ among participants with more than 10 years of clinical experience $(\mathrm{p}<0.05)$. The overall WPV in the current study was $38 \%$. Male participants have reported a higher prevalence of violence (42.8\%) than their female counterparts (32.4\%) and these differences were statistically significant $(\mathrm{p}<0.05)$. There was not much difference in WPV experience among the medical and dental profession. Although respondents with more than 10 years of clinical practice have experienced more violence, statistically it was not significant.

In the present study, around $51.4 \%$ of the respondents believe that the lack of communication and negligence of the doctor also plays a crucial role in violence against them. These values increase to $57 \%$ among females and $58 \%$ among medical practitioners $(\mathrm{p} \leq 0.05)$.

\begin{tabular}{|ccc|}
\hline Age Group & Mean & SD \\
24 to 77 & 37.6 & 11.4 \\
\hline Gender & Frequency & Percentage (\%) \\
Male & 236 & 53.6 \\
Female & 204 & 46.4 \\
& Field of Practice & \\
Medical & 220 & 50 \\
Dental & 220 & 50 \\
& Years of Experience & \\
Less than 5 years & 182 & 41.4 \\
5 to 10 years & 148 & 33.6 \\
More than 10 years & 110 & 25 \\
Total & $\mathbf{4 4 0}$ & $\mathbf{1 0 0}$ \\
\hline Table 1. Demographic Details of the Study Participants \\
\hline
\end{tabular}

Around $56.4 \%$ of the total respondents believe that the current law to prevent WPV against doctors in India is not sufficient and has to be made stringent. A greater percentage of males and medical practitioners correspond to the same. More than half of the participants $(61.4 \%)$ recommended doctors to carry weapons for self-defence against violence and these values rise to $71 \%$ among individuals with more than 10 years of clinical experience $(\mathrm{p}=0.05)$. Around $70.5 \%$ believed that media publicity plays a crucial role in the increasing trend of WPV against healthcare professionals (Table 2).

Table 2 describes the binary logistics regression analysis of age, gender, qualification and years of experience as the predictor variables with workplace violence as the dependent variable. It was found that males were 1.56 times more likely to experience violence than females which was statistically significant $(\mathrm{p}=0.02)$. Among the study participants who have experienced WPV, around $58.2 \%$ was psychological which included emotional attacks like verbal abuse, use of harsh words, speaking in an aggressive tone, cursing and threats. About $18.2 \%$ have experienced physical form of violence (Figure 1). When questioned about the reason for increasing violence against healthcare professionals, about one-third of the respondents (32\%) believed that patient's poor health literacy was the major reason which was followed by doctorpatient relationship, cost \& quality of health care and poor judicial system (Figure 2).

In the current study, nearly half of the participants (48\%) responded that the perpetrators of violence against doctors are the patient's relatives or the individuals accompanying them (Figure 3). About $41.2 \%$ of the participants who have experienced violence developed fear and anxiety and most of them lost motivation in their clinical practice and they stopped giving proactive advice (Figure 4).

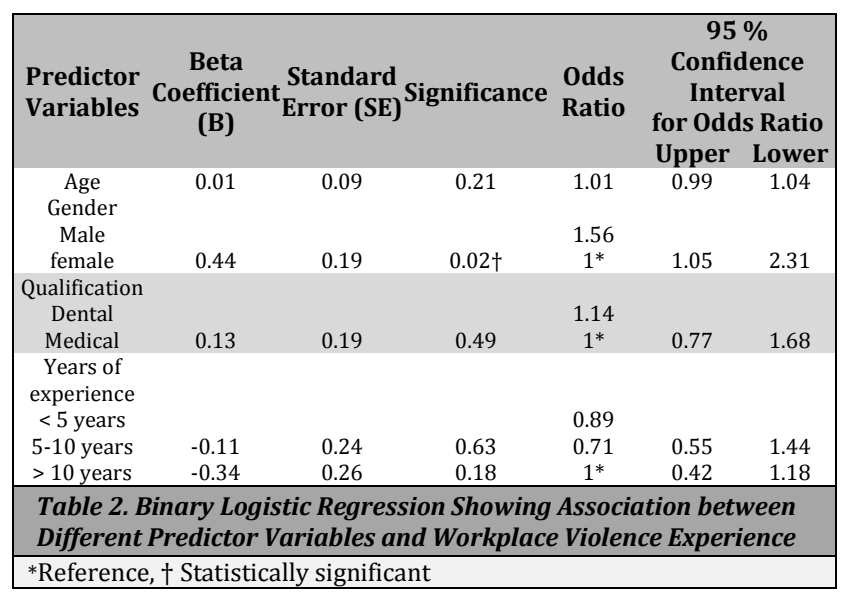



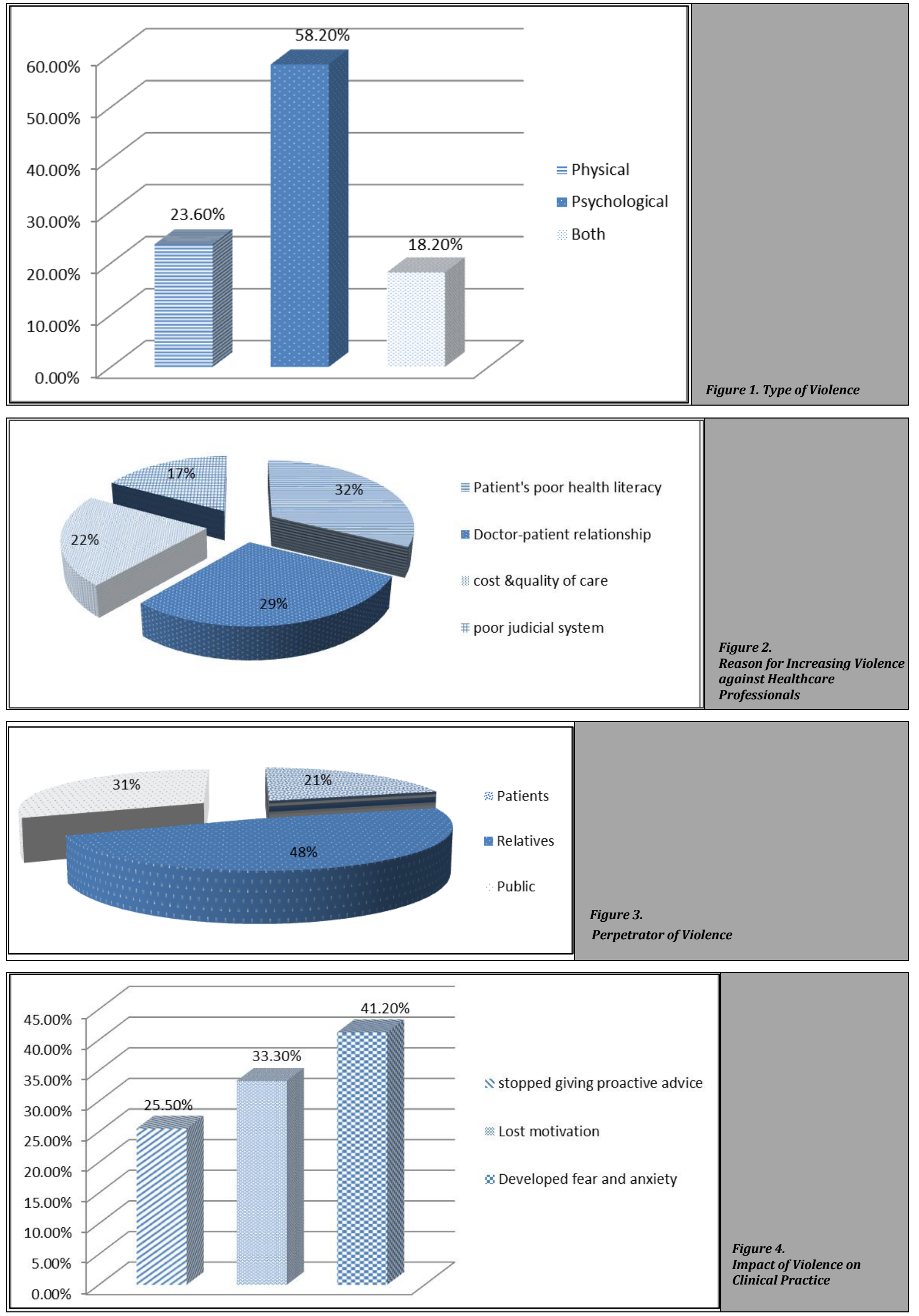


\begin{tabular}{|c|c|c|c|c|c|c|c|c|c|c|}
\hline \multirow[b]{2}{*}{ Questions } & \multicolumn{3}{|c|}{ Gender (\%) } & \multicolumn{3}{|c|}{ Field of Practice (\%) } & \multicolumn{4}{|c|}{ Experience (\%) } \\
\hline & Male & Female & \begin{tabular}{|c|} 
P - \\
Value
\end{tabular} & Medical & Dental & $\begin{array}{c}P \text { - } \\
\text { value }\end{array}$ & $\begin{array}{l}<5 \\
\text { Years } \\
\end{array}$ & \begin{tabular}{|c|}
$5-10$ \\
Years \\
\end{tabular} & $\begin{array}{c}10 \\
\text { Years } \\
\end{array}$ & $\begin{array}{c}P \text { - } \\
\text { Value }\end{array}$ \\
\hline $\begin{array}{c}\text { Awareness of increasing workplace violence. } \\
\text { Yes } \\
\text { No } \\
\end{array}$ & $\begin{array}{c}206(87.3) \\
30(12.7) \\
\end{array}$ & $\begin{array}{c}186(91.2) \\
18(8.8) \\
\end{array}$ & 0.2 & $\begin{array}{c}192(87.3) \\
28(12.7) \\
\end{array}$ & $\begin{array}{c}200(90.9) \\
20(9.1) \\
\end{array}$ & 0.2 & $\begin{array}{c}166(91.2) \\
16(8.8) \\
\end{array}$ & $\begin{array}{c}124(83.8) \\
24(16.2) \\
\end{array}$ & $\begin{array}{c}102(92.7) \\
8(7.3) \\
\end{array}$ & $0.03^{*}$ \\
\hline $\begin{array}{c}\text { Experienced workplace violence } \\
\text { Yes } \\
\text { No } \\
\end{array}$ & $\begin{array}{l}101(42.8) \\
135(57.2)\end{array}$ & $\begin{array}{c}66(32.4) \\
138(67.6)\end{array}$ & $0.03 *$ & $\begin{array}{c}80(36.4) \\
140(63.6) \\
\end{array}$ & $\begin{array}{c}87(39.5) \\
133(60.5)\end{array}$ & 0.5 & $\begin{array}{c}71(39) \\
111(61)\end{array}$ & $\begin{array}{l}50(33.8) \\
98(66.2) \\
\end{array}$ & $\begin{array}{l}46(41.8) \\
64(58.2)\end{array}$ & 0.39 \\
\hline $\begin{array}{c}\text { Doctors negligence also a cause for Workplace Violence. } \\
\text { Yes } \\
\text { No } \\
\end{array}$ & $\begin{array}{l}110(46.6) \\
126(53.4)\end{array}$ & $\begin{array}{r}116(57) \\
88(43)\end{array}$ & $0.03^{*}$ & $\begin{array}{c}128(58.2) \\
92(41.8)\end{array}$ & $\begin{array}{r}98(44.5) \\
122(55.5)\end{array}$ & 0.05 & $\begin{array}{c}100(54.9) \\
82(45.1)\end{array}$ & $\begin{array}{l}72(48.6) \\
76(51.4)\end{array}$ & $\begin{array}{c}54(49.1) \\
56(50.9)\end{array}$ & 0.45 \\
\hline $\begin{array}{c}\text { Need strict law to prevent violence. } \\
\text { Yes } \\
\text { No } \\
\end{array}$ & $\begin{array}{c}150(63.6) \\
86(36.4) \\
\end{array}$ & $\begin{array}{c}98(48) \\
106(52) \\
\end{array}$ & $0.01^{*}$ & $\begin{array}{c}136(61.8) \\
84(38.2) \\
\end{array}$ & $\begin{array}{l}112(50.9) \\
108(49.1) \\
\end{array}$ & $0.02^{*}$ & $\begin{array}{l}92(50.5) \\
90(49.5)\end{array}$ & $\begin{array}{l}88(59.5) \\
60(40.5)\end{array}$ & $\begin{array}{l}68(61.8) \\
42(38.2) \\
\end{array}$ & 0.11 \\
\hline $\begin{array}{c}\text { Recommend doctors to use weapons for self-defence. } \\
\text { Yes } \\
\text { No }\end{array}$ & $\begin{array}{c}152(64.4) \\
84(35.6)\end{array}$ & $\begin{array}{r}118(57.8) \\
86(42.2)\end{array}$ & 0.15 & $\begin{array}{r}132(60) \\
88(40)\end{array}$ & $\begin{array}{c}138(62.7) \\
82(37.3)\end{array}$ & 0.55 & $\begin{array}{c}108(59.3) \\
74(40.7)\end{array}$ & $\begin{array}{l}84(56.8) \\
64(43.2)\end{array}$ & $\begin{array}{l}78(71) \\
32(29)\end{array}$ & $0.04^{*}$ \\
\hline $\begin{array}{c}\text { Media plays a key role in increasing violence. } \\
\text { Yes } \\
\text { No }\end{array}$ & $\begin{array}{c}174(73.7) \\
62(26.3)\end{array}$ & $\begin{array}{c}136(66.7) \\
68(33.3)\end{array}$ & 0.10 & $\begin{array}{c}152(69.1) \\
68(30.9)\end{array}$ & $\begin{array}{c}158(71.8) \\
62(28.2)\end{array}$ & 0.5 & $\begin{array}{c}118(64.8) \\
64(35.2)\end{array}$ & $\begin{array}{c}110(74.3) \\
38(25.7)\end{array}$ & $\begin{array}{l}82(74.5) \\
28(25.5)\end{array}$ & 0.09 \\
\hline Table & Responses & of the Part & ticipan & Regarding & Workplace & e Viole & & & & \\
\hline
\end{tabular}

\section{DISCUSSION}

Violence against doctors is detrimental to the society. It can directly influence the physical and psychological well-being of victims. Furthermore, WPV can cause nonattendance which can be either temporary or permanent that can damage the morale of healthcare workers. Violence in the health segment can profoundly affect the efficiency and effectiveness of the healthcare system, predominantly in developing countries like India. ${ }^{8}$

In the current study, we have included health care professionals who have a private practice. Participants from the medical and dental field were selected to identify any significant differences in their responses. We have also categorized them into three groups depending upon their clinical experience to study their response pattern.

Most of the participants were aware of the increasing trend in WPV against doctors in India. The prevalence of WPV in the present study was $38 \%$ which was comparable to a study conducted by Ferri et al. ${ }^{9}$, but a study Sun et al. ${ }^{8}$ showed a high prevalence of $83 \%$. In our study, we found that females experience a significantly lower percentage of violence than males, but a study conducted by Viottini et al. 4 in Italy showed a high prevalence of violence against females. It may be because our study involved only doctors whereas the study conducted in Italy involved nurses and the majority of the nurses are females. Studies conducted by Berlanda et al. ${ }^{4}$ and Alsaleem et al. ${ }^{10}$ found no significant gender differences.

Half of the participants in our study responded that negligence and lack of proper communication from the doctor also contribute significantly to WPV against them. Since most of the patients visiting a private clinic are from different socioeconomic background with varying levels of literacy, the aetiology in most of the incidents can be traced down to inadequate doctor-patient communication. In this current age of the internet, most of the information is accessible online and it is the responsibility of the treating doctor to give them accurate and authentic information about the cause of the disease, its progression, the various treatment options, the prognosis and the costs involved in the treatment. However, when this information is not satisfactorily communicated, it leads to severe consequences. ${ }^{6}$
More than fifty per cent of the study participants believed that the law against WPV against doctors in India needs to be more stringent. In India, most of the states have passed the "Protection of Medicare Service Persons and Medicare Service Institutions (Prevention of Violence and Damage to Property) Act", also known as the Medical Protection Act (MPA). It covers doctors affiliated to institutions as well as independent practitioners and any attack against them and their properties can lead to a jail term up to three years and a fine of INR 50,000 . However, since this Act doesn't feature in the Indian Penal Code (IPC) or Code of Criminal Procedure (CrPC), it is often challenging to approach the law enforcement agency for help or to file a grievance against suspects. ${ }^{11}$

We observed that nearly two-thirds of the doctors recommended carrying weapons for self-defence against violence. The lack of faith in the judicial process and the mob mentality which is more predominant in our society were significant contributory factors for this response. While this finding gets a few eye-balls roll, but in the long run, it can be a way forward for one's self-protection.

Most of the respondents believed that sensational media coverage often ignoring comprehensive details contribute significantly to WPV against them. On the other hand, it served to work against the patient's welfare. Healthcare professionals will now be hesitant to handle complicated cases; hence countless precious lives that could have been saved will be lost. ${ }^{12}$

Psychological violence is the most prevalent form experienced by the participants in the current study which is in accordance with most of the studies reported in the literature $4,8,9,13,14$

In our study, the perpetrator of violence in most of the cases is the patient's relatives or individuals accompanying them. These findings are in sharp contrast with most of the studies 3, 4, 9, 10,15, where the aggressor is the patient.

Nearly half of the doctors who have experienced some form of violence in their clinical practice developed fear and anxiety. They also lost motivation and some have stopped giving proactive advice to their patients. Almost all the studies reported in the scientific literature had similar findings. This can result in reduced empathy aptitude of the health care professional and affect the quality of the care provided. 


\section{Limitations}

The participants for our study were selected using a nonprobabilistic convenient sampling method due to logistics and other practical difficulties, which could potentially prevent the generalization of our findings.

The study design used a retrospective cross-sectional approach which depends upon the ability of the respondents to recall events occurred in their lifetime. This can result in memory or recall bias which is one of the limitations of the study.

We collected data only from medical and dental doctors, whereas WPV has been reported among other health care professionals like nurses, receptionists and other auxiliaries. ${ }^{10,13,15}$ Although it is beyond the scope of the current study, we consider it as a potential limitation. Another important limitation of the study is the non-availability of extensive data regarding the perpetrator of violence such as their age, gender, state of mind and other socio-demographic characteristics useful to identify potential risk factors.

\section{CONCLUSIONS}

The current study concludes that violence against doctors in Chennai is frequent. Continuing Medical Education programs by experts in the field of communication can be conducted to improve the communication skills of health care professionals. This can also be made mandatory for doctors practising medicine in India. Healthcare staff should be trained to identify, manage and prevent violent situations adequately. The authorities can develop a standard operating procedure (SOP) for violence and the staff should be made clear of his / her role in such situations. Media has a significant role. They should provide accurate information and should highlight the issues from both sides of an event. A central government law for the prevention of violence against healthcare professionals and institutions should be developed with adequate changes in the Indian Penal Code (IPC) making such violence a nonbailable offence with stringent punishment.

Health care professional's attitude should be reoriented towards ever-changing structure and perceptions of society. Classical doctor-patient relationships do not work anymore, and the patient should be involved in decision-making matters relating to their health. A nationwide study can be conducted using probability sampling methodology involving various sub-groups of the healthcare personnel to investigate the prevalence, risk factors and motivation of WPV against them, including substantial data about the perpetrator of such violence. The results of the study can be utilized to develop adequate prevention strategies on a national level.

The authors acknowledge all the healthcare professionals who have participated in the study.

Financial or Other Competing Interests: None.

\section{REFERENCES}

[1] World Health Organization. Violence and injury prevention: violence against health workers. https://www.who.int/violence_injury_prevention/viole nce/workplace/en/

[2] National Institute of Occupational Safety and Health. Violence occupational hazards in hospitals. https://www.cdc.gov/niosh/docs/2002101/default.html

[3] Viottini E, Politano G, Fornero G, et al. Determinants of aggression against all health care workers in a large-sized university hospital. BMC Health Serv Res 2020;20:215.

[4] Berlanda S, Pedrazza M, Fraizzoli M, et al. Addressing risks of violence against healthcare staff in emergency departments: the effects of job satisfaction and attachment style. Biomed Res Int 2019;2019:1-12.

[5] Phillips JP. Workplace violence against health care workers in the United States. N Engl J Med 2016;374(17):1661-9.

[6] Mishra S. Violence against doctors: the class wars. Indian Heart J 2015;67(4):289-92.

[7] Industrial economist. Chennai - The Medical Capital of India.

http://industrialeconomist.com/2019/01/30/chennaithe-medical-capital-of-india/

[8] Sun P, Zhang X, Sun Y, et al. Workplace violence against health care workers in North Chinese hospitals: a crosssectional survey. Int J Environ Res Public Health 2017;14(1):96.

[9] Ferri P, Silvestri M, Artoni C, et al. Workplace violence in different settings and among various health professionals in an Italian general hospital: a cross-sectional study. Psychol Res Behav Manag 2016;9:263-75.

[10] Alsaleem SA, Alsabaani A, Alamri RS, et al. Violence towards healthcare workers: a study conducted in Abha City, Saudi Arabia. J Family Community Med 2018;25(3):188-93.

[11] Sirur S. There is a law to protect doctors from assault but this is why it doesn't work. The Print https://theprint.in/india/there-is-a-law-to-protectdoctors-from-assault-but-this-is-why-it-doesntwork/250217/

[12] Nagpal N. Incidents of violence against doctors in India: can these be prevented? Natl Med J India 2017;30(2):97100.

[13] Hahn S, Müller M, Hantikainen V, et al. Risk factors associated with patient and visitor violence in general hospitals: results of a multiple regression analysis. Int J Nurs Stud 2013;50(3):374-85.

[14] Ahmed F, Memon MK, Memon S. Violence against doctors, a serious concern for healthcare organizations to ponder about. Ann Med Surg (Lond) 2017;25:3-5.

[15] Spector PE, Zhou ZE, Che XX. Nurse exposure to physical and nonphysical violence, bullying, and sexual harassment: a quantitative review. Int J Nurs Stud 2014;51(1):72-84. 